\title{
Connotation Analysis and Paradigm Shift of Teaching Design under Artificial Intelligence Technology
}

\author{
https://doi.org/10.3991/ijet.v16i05.20287 \\ Jian Huang \\ Nanjing Institute of Technology, Nanjing, China \\ Gang Shen \\ Changzhou University, Changzhou, China \\ Xiping Ren $(\bowtie)$ \\ Zhejiang Normal University, Jinhua, China \\ University of Rostock, Rostock, Germany \\ huanjenjit. edu.cn
}

\begin{abstract}
The influence of artificial intelligence technology on teaching design is explored to improve teaching efficiency. First, artificial intelligence is introduced and its impacts on teaching design are analyzed. Second, the connotation of the paradigm of teaching design and the paradigm shift for teaching design are explored using the paradigm shift analysis framework. Finally, the changes in teaching design under artificial intelligence are analyzed, and the impacts of artificial intelligence on teaching activities are investigated. The results show that the application of artificial intelligence technology has led to different levels of change in the six elements of teaching design, including teaching objectives, service objects (teachers and students), teaching content, teaching media, teaching environment, and teaching evaluation. The connotation and paradigm shift of the teaching design are introduced from the four elements based on the artificial intelligence technology. It is found that artificial intelligence technology can enhance the learning ability and cognitive ability of students to a certain extent while improving the teaching efficiency and learning efficiency. The investigation proves that the teaching design based on artificial intelligence technology can be applied to teaching activities, thereby improving the learning efficiency of students and the teaching efficiency of teachers.
\end{abstract}

Keywords - Artificial intelligence technology; paradigm shift; teaching design; teaching efficiency

\section{Introduction}

The rapid development of artificial intelligence technology has provided reliable technical support for the development and reform of the education field. Intelligent education has now become an important part of artificial intelligence strategy in 
China. The modernization of education refers to reforming the current education mode and promoting the pace of ecological reconstruction under the conditions of artificial intelligence, big data, and the Internet of Things [1]. Worldwide scholars have pointed out that promoting the development of applicable learning environments and tools is the core concept of artificial intelligence education. At the same time, it is necessary to open the black box of learning in this process and explore the motivation and process of learning [2]. Some scholars have proposed that the purpose of educational artificial intelligence is to provide a better teaching environment, allowing teachers and students to participate in the teaching better. With the help of the developed computer technology, the teaching platform is optimized and improved to create a more suitable environment. It is pointed out that it is possible to combine the artificial intelligence education and robotics in the future, so as to provide students with technology designed for teaching and learning [3]. With the continuous development of intelligent platform technology, some scholars have explored the combination of artificial intelligence and education. In addition, they have designed an intelligent teaching system, which can simulate student learning and support the applicability of knowledge, and be able to establish the social contacts with learners autonomously [4]. In the continuous integration of artificial intelligence and education, the traditional learning platform has to be transformed. As an interactive learning ecosystem, the platform is equipped with an adaptive system that can provide a better service experience and data support for relevant personnel [5]. Scholars worldwide have conducted researches on artificial intelligence, developed the educational robots to accompany academic learning, and explored the impact it has on student learning [6].

Chinese scholars have proposed the goal and connotation characteristics of intelligent education by combining the results of worldwide scholars and the development status of artificial intelligence education in China [7]. Some scholars have analyzed the impact of artificial intelligence on the roles of teachers and students to point out that artificial intelligence can't substitute the human teachers completely. Other scholars have explored the learning environment under artificial intelligence, and analyzed it from the study space, the connotation, and characteristics of the smart classroom [8]. The development of artificial intelligence has affected all aspects of education in China, showing a diversified development trend. However, the combination of theory and practice is not close enough, and there is a lack of effective teaching design in the current application.

Based on the existing results, the impact of artificial intelligence on teaching design, the connotation and framework of the paradigm shift, as well as the connotation and paradigm shift of teaching design are explored based on artificial intelligence technology. Besides, the impacts of artificial intelligence technology on teaching activities are analyzed in this study. 


\section{Methods}

\subsection{Artificial intelligence}

Artificial intelligence is defined as a comprehensive discipline that simulates and expands human brain functions through computers. According to the current results, it can be divided into artificial intelligence, strong artificial intelligence, and super artificial intelligence based on the strength of artificial intelligence. Weak artificial intelligence is developed for a specific field and is only good at one type of problemsolving methods. Strong artificial intelligence has reached artificial intelligence comparable to that of the human brain. Super artificial intelligence has been ahead of the level of the human brain, and its application has covered all areas [9].

The application of artificial intelligence in education is described as follows. Helping teachers complete the teaching tasks with its image, speech recognition, and semantic technology has become its fundamental functions. In addition, its intelligent graph analysis can help students perform virtual learning and other functions. The application of artificial intelligence in education is realized in different forms, such as subjectivity and auxiliary [10]. The teaching functions in its two forms are shown in Figure 1 below.

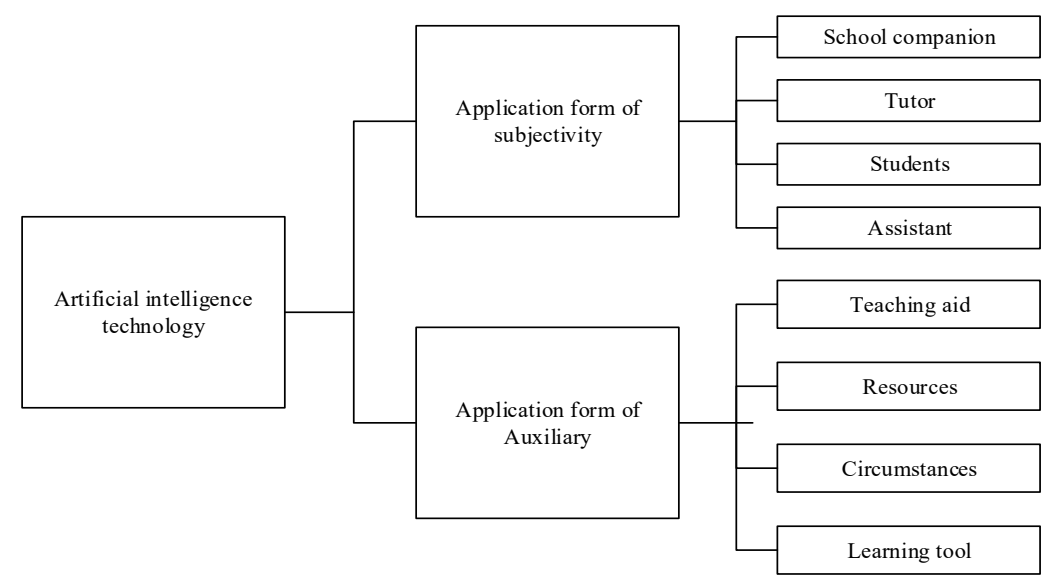

Fig. 1. Application form of artificial intelligence in the teaching system

\subsection{Teaching design}

The teaching design is defined as follows based on the current literature. The systematic methods are adopted to transform learning theories and teaching theories into specific plans for teaching objectives, teaching contents, teaching methods, teaching strategies, and teaching evaluation to achieve a systematic process of teaching and learning. Teaching design integrates all elements in the teaching system, which is regarded as a whole. Then, it is planned, implemented, and evaluated so that the system performance can be excellent enough [11]. Due to the continuous 
development and progress of the times, the teaching system composed of elements also changes dynamically. Teaching design can play a predictive role in teaching activities, and can effectively determine the teaching objectives, teaching contents, teaching methods, and teaching processes. Only when faced with the change of elements in teaching activities, can the application effect of intelligent technology in education and teaching be fully exerted.

\subsection{Teaching design under the background of artificial intelligence}

The application of artificial intelligence technology has brought some great changes to teaching design. The teaching objectives, service objects (teachers and students), teaching contents, teaching media, teaching environment, and teaching evaluation involved in current teaching design are analyzed [12]. The effect of artificial intelligence on the elements of teaching design is shown in Figure 2 below.

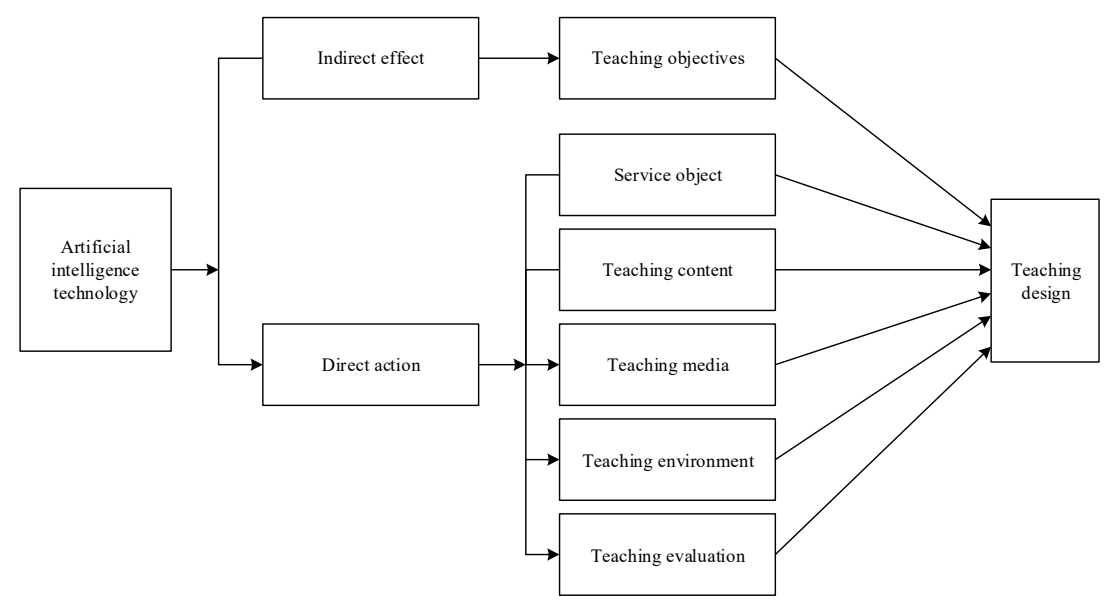

Fig. 2. Effect of artificial intelligence on teaching design

Change of teaching objective: The production methods of all walks of life are moving towards automation with the development of artificial intelligence technology, resulting in corresponding changes in the industrial structure and labor market system. The teaching objective in the sense of traditional education is to make students become accomplished talents in various industries. However, the teaching objectives have changed accordingly with the social structure changes brought by artificial intelligence technology. The current teaching objective is to pay more attention to independent learning ability, agile thinking ability, innovation and creativity, and strong adaptability of students.

Change of service object: The development of artificial intelligence technology has changed the service object of teaching, which means that the relationship between subject and object is changed. With the continuous development of society, the teaching subject has undergone constant changes, as shown in Figure 3 below. 


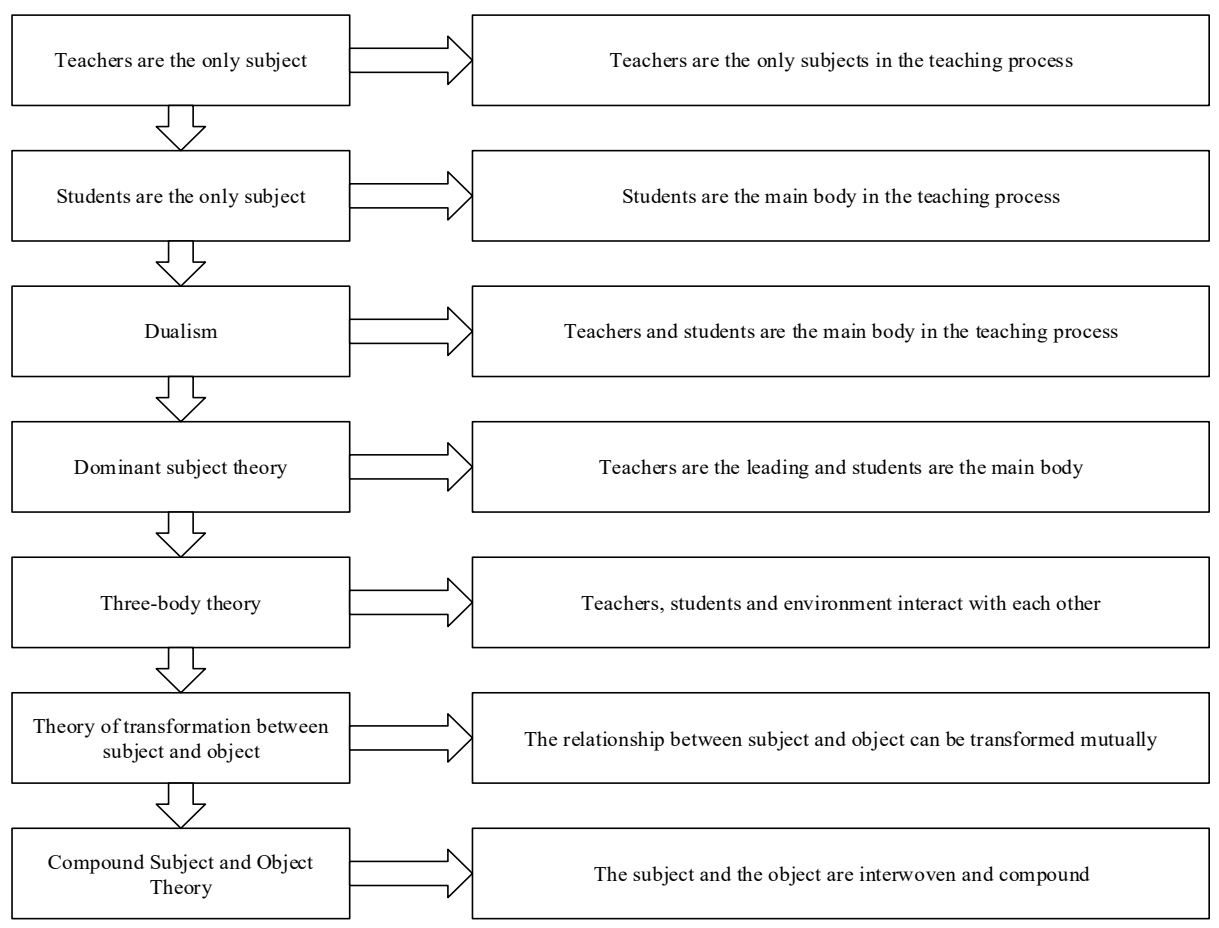

Fig. 3. The changing process of the teaching subject

The development of artificial intelligence technology has changed the way in which service objects participate in teaching. At the same time, the ownership of information resources has also changed, and the tasks undertaken by the service objects have changed accordingly. However, the only constant is that teachers and students are still indispensable factors.

Change of teaching content: the teaching content includes the knowledge, ability, thoughts, and behaviors transmitted by the school to students at all levels. Artificial intelligence technology acts on the teaching system, making the teaching content change. The knowledge related to artificial intelligence and humanities is increased day by day. Then, the advent of the intelligent age requires the school focus on cultivating the human-computer collaboration capabilities of all students.

Change of teaching media: the teaching process refers to the process of collecting, processing, and using information. The media adopted in this process is called teaching media, which is one of the important components of teaching design. It carries the most basic educational information and is also a basic teaching resource. It is also a representative of the development level of education modernization. With the continuous advancement of social science and technology, the teaching media is constantly changing, as shown in Figure 4 below. 


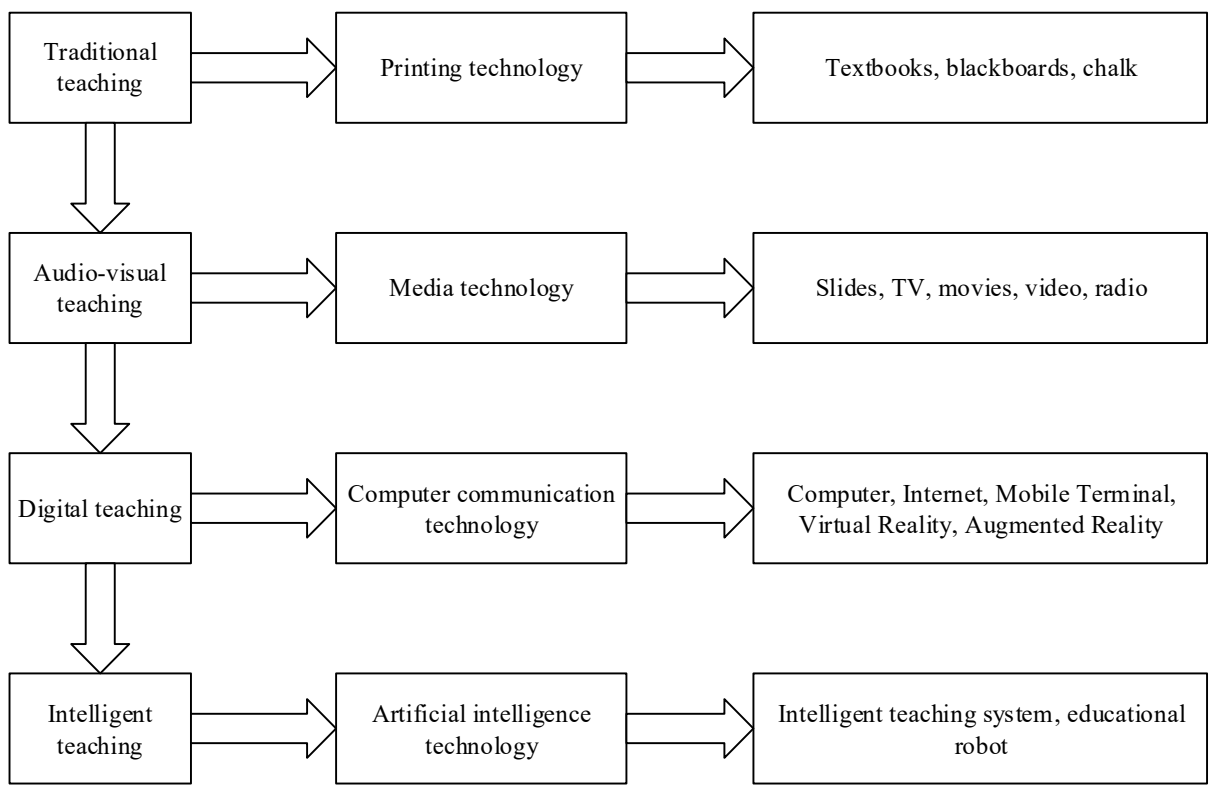

Fig. 4. The changing process of teaching media

The development of artificial intelligence technology may replace the dominant position of human individuals in knowledge practice, enabling the knowledge practice have a deeper level of automation. It shares the burden of teachers and realizes more personalized learning process of students.

Change of teaching environment: the teaching environment can be divided into the broad and narrow one. In a broad sense, the teaching environment includes all the physical and psychological environments involved in the teaching activities. The narrow-level teaching environment focuses on the conditions that affect the teaching activities within the class, including the teacher-student relationship, class size, and class atmosphere. The development of artificial intelligence technology helps the physical environment of educational activities develop towards flexibility and hierarchy. It allows the generation methods of educational resources to develop from static to dynamic and personalized processes, so that the human-computer interaction of teaching activities can be more powerful and natural. Then, the online and offline teaching environment can be combined seamlessly.

Change of teaching evaluation: the traditional way of evaluating the teaching of learners is often achieved through the semester summary or the final test scores of the teaching courses. This method focuses more on the evaluation of learning results and group development of students, and pays less attention to the evaluation of processes and individual development of the students. The development of artificial intelligence technology promotes the evaluation of students move forward in a comprehensive direction, and the performance of students in the learning process is also added to the evaluation. Thus, the evaluation method of students becomes more bidirectional and multidirectional. 


\subsection{Paradigm shift of teaching design}

Paradigm shift: the paradigm shift has not been defined clearly throughout previous results. However, it is possible to determine whether the process of paradigm shift has occurred using the symbolic generalization, promised beliefs, unanimously recognized values, and common examples that can be imitated. In the determination process, the focus is on the community members contained in the content of this process. The occurrence of these four elements is all activities that are unanimously recognized by members of the community or co-occurred [13]. The analysis framework of the paradigm shift is shown in Figure 5 below.

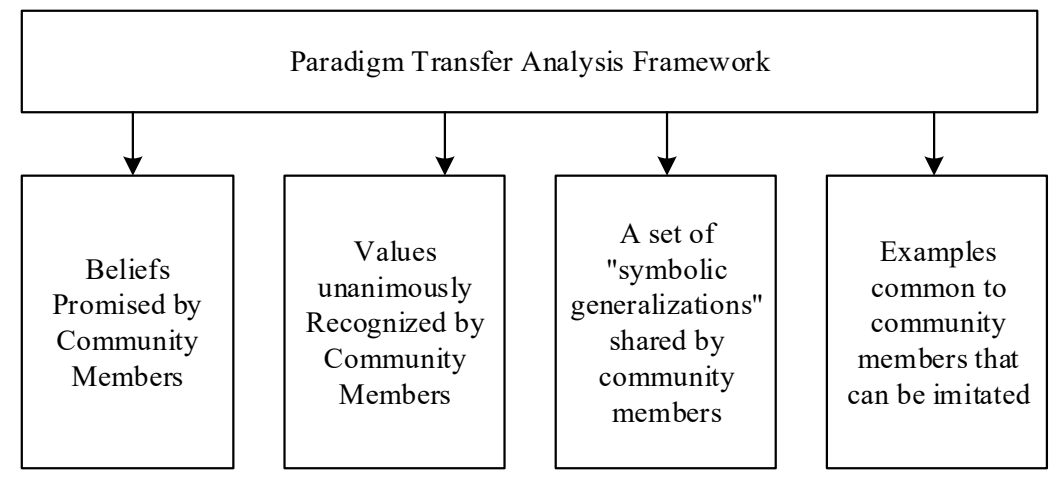

Fig. 5. Analysis framework of the paradigm shift

Paradigm shift of teaching design activities: in teaching design, existing law theories and techniques will be applied to advance the pace of teaching innovation. In this process, the diversity of researchers' perspectives, research objectives, and research methods lead to the diversity of theories. As a result, its development process has been affected by many aspects, eventually producing a variety of paradigms [14]. These paradigm theories contain common research methods, ideas, and guiding examples. Each paradigm highlights a component of teaching design. The teaching design and its paradigm have changed as society is constantly evolving. Thus, each paradigm occupies a specific dominant position in a certain period.

\subsection{Paradigm shift of teaching design under artificial intelligence}

The development of artificial intelligence technology has changed the way of teaching design, which has caused a paradigm shift in teaching design. Artificial intelligence is a technical factor. Thus, the paradigm shift in teaching design is mainly analyzed from the technical changes in teaching design. The paradigm shift of teaching design is periodic. Whether the paradigm shift occurred in the artificial intelligence stage requires a comparative analysis with the previous period of the artificial intelligence development stage (pre-intelligent period) to obtain the answer [15]. 
The pre-intelligent teaching design stage mainly includes three categories: computer-assisted teaching design, multimedia teaching design, and informatized teaching design.

Computer-assisted teaching: the use of computers for assisted teaching mainly refers to the use of computers to share part of the teaching tasks, and to assist teachers in teaching activities through collaborative processing [16]. In essence, the teacher is the source of information and releases teaching information; the computer is a tool for information transmission and processing and sends the processed information to the students; and students mainly acquire knowledge from the teaching information passed to them. The computer-assisted teaching design has not completely disengaged from the impact of media design concepts due to technical limitations.

Multimedia teaching design: the emergence of multimedia technology provides an effective solution for the organization and management of various media information. The application of multimedia technology to teaching activities is mainly based on a systematic approach, and the modern teaching methods are realized by optimizing the multimedia combination [17]. The focus of multimedia teaching design is to guide students to obtain a unified psychological representation from the teaching resources under different presentation methods by selecting appropriate modern teaching media tools (presentation methods of teaching resources) according to the needs of teaching objectives and the teaching content, thereby obtaining new knowledge. Multimedia teaching design mainly presents different information knowledge through different information processing methods and correlates different information expression methods. It helps students to acquire knowledge better and to optimize the representation method of as few learning resources as possible.

Informatized teaching design: informatized teaching design is mainly the result of the combined effect of informatized teaching environment, diversified information resources, as well as frequent sharing and interaction of teaching information. The informatized teaching design takes students as the teaching center, makes full use of modern technical resources, and ensures the design of each link of the teaching process more reasonable with a view to optimizing the teaching process.

An overall analysis reveals that there is no significant change in the teaching belief, value, and teaching symbols of computer-assisted teaching and multimedia teaching design. Thus, it can be regarded as a unified multimedia teaching.

Artificial intelligence teaching design: technology no longer only affects the teaching design through tools and means in the context of artificial intelligence. Artificial intelligence technology is comprehensive and has penetrated into all aspects of teaching design elements, teaching process, and teaching service objects. The purpose is to achieve the integration of various elements in the teaching system with information technology such as teaching objectives, teaching content, and teaching environment.

Artificial intelligence mainly has two application forms: subjectivity and auxiliary. The two application forms have different functions. The application form, design elements, and characteristics of artificial intelligence are shown in Figure 6 below. 


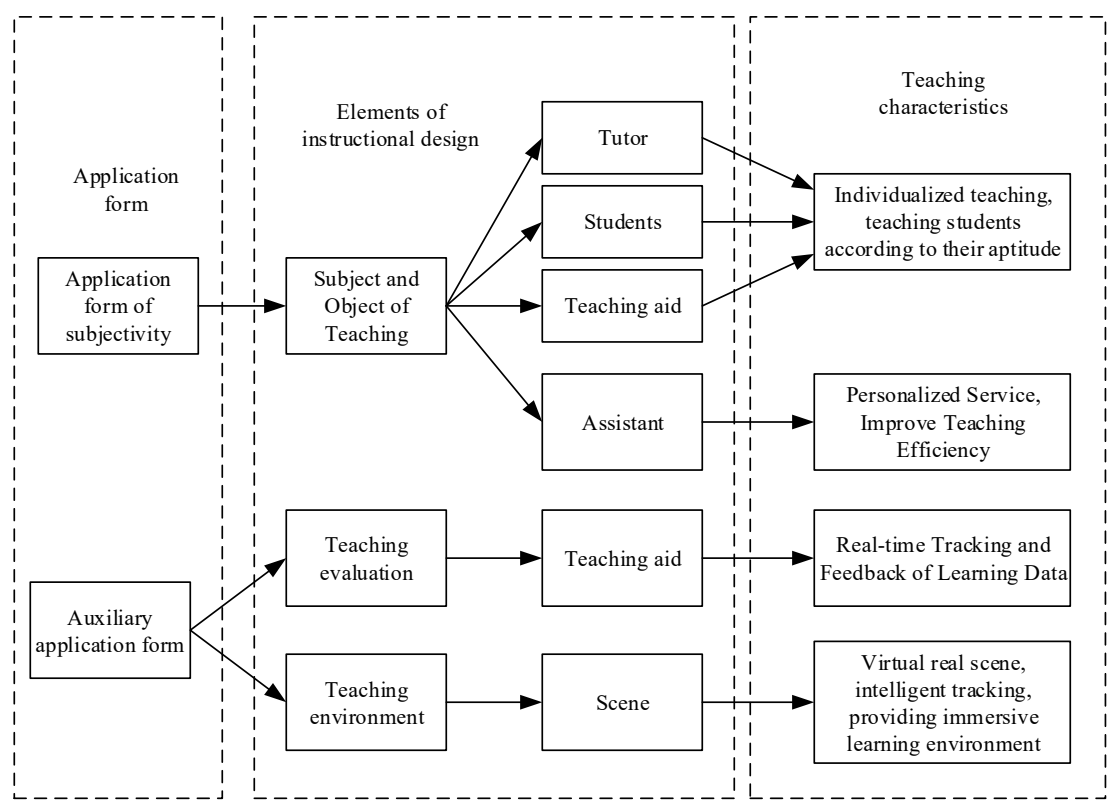

Fig. 6. Application of artificial intelligence in teaching design

\subsection{Analysis of teaching design effectiveness based on artificial intelligence}

To verify the achievements of artificial intelligence teaching design, 100 students are divided into two groups: an experimental group and a control group. Teaching design is performed on the experimental group using artificial intelligence technology. The control group is taught common teaching design methods. The empirical analysis of the effects is conducted from academic performance, learning attitude (learning attitude, emotional experience, self-cognition, and behavioral tendency), and teaching satisfaction.

\section{$3 \quad$ Results and Analysis}

\subsection{Paradigm shift analysis of teaching design under artificial intelligence}

From the application form and four elements of the paradigm shift, multimedia teaching design, informatized teaching design, and artificial intelligence teaching design are compared to judge the paradigm shift of teaching design brought by artificial intelligence technology. The comparison results are shown in Table 1 below. 
Table 1. Analysis results of the paradigm shift of teaching design under artificial intelligence

\begin{tabular}{|l|l|l|l|}
\hline & \multicolumn{1}{|c|}{$\begin{array}{c}\text { Multimedia teaching } \\
\text { design }\end{array}$} & $\begin{array}{c}\text { Informatized teaching } \\
\text { design }\end{array}$ & \multicolumn{1}{|c|}{$\begin{array}{c}\text { Artificial intelligence teaching } \\
\text { design }\end{array}$} \\
\hline $\begin{array}{l}\text { Application } \\
\text { form }\end{array}$ & Teaching media & $\begin{array}{l}\text { Teaching media, teaching } \\
\text { methods, teaching means }\end{array}$ & $\begin{array}{l}\text { Full penetration and integration of } \\
\text { teaching objectives, teaching } \\
\text { content and teaching environment }\end{array}$ \\
\hline Belief & $\begin{array}{l}\text { Media concept: Using } \\
\text { technology }\end{array}$ & $\begin{array}{l}\text { Tool concept: using } \\
\text { technology }\end{array}$ & $\begin{array}{l}\text { Ecological concept: human-machine } \\
\text { integration }\end{array}$ \\
\hline Value & $\begin{array}{l}\text { Maximizing the efficiency } \\
\text { of knowledge transfer }\end{array}$ & $\begin{array}{l}\text { Involving learners in the } \\
\text { process of building a } \\
\text { knowledge system }\end{array}$ & $\begin{array}{l}\text { Improving the personalization and } \\
\text { precision of teaching activities }\end{array}$ \\
\hline Symbol & Stability, linearity & Stability, nonlinearity & Dynamics, nonlinearity \\
\hline Example & $\begin{array}{l}\text { Multimedia combination } \\
\text { teaching design }\end{array}$ & $\begin{array}{l}\text { Mixed and flipped } \\
\text { classroom teaching design }\end{array}$ & $\begin{array}{l}\text { Based on the teaching mode of } \\
\text { technical connectivity, robot- } \\
\text { assisted teaching }\end{array}$ \\
\hline
\end{tabular}

Table 1 suggests that artificial intelligence technology has brought a paradigm shift to the teaching design system. The four elements of the paradigm shift (belief, value, symbol, and example) in the community of teaching design have changed accordingly based on artificial intelligence technology. Therefore, it is proved that artificial intelligence technology has caused a paradigm shift in teaching design. In addition, it can be seen that the application form of teaching design based on artificial intelligence technology has also changed accordingly.

\subsection{Analysis of learning achievements for the application of artificial intelligence teaching design}

The actual application effect of artificial intelligence technology is analyzed in teaching design from learning achievements. The analysis results are shown in Figure 7 below.

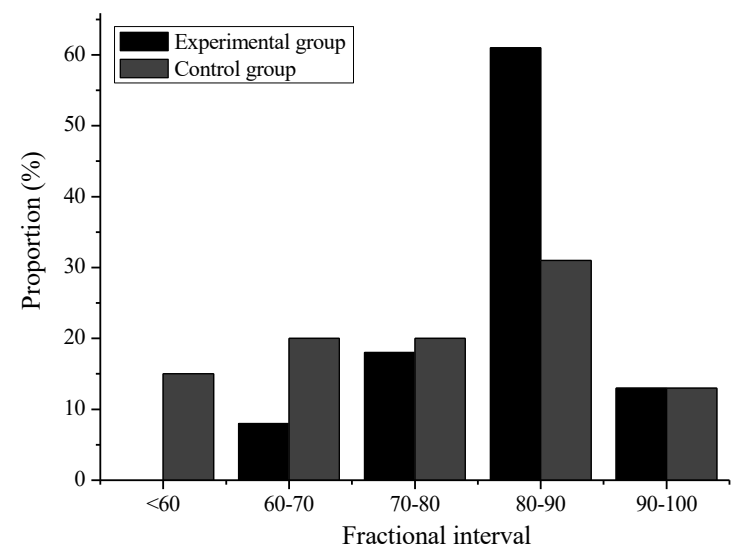

Fig. 7. Comparative analysis of students' achievements under different teaching design methods 
Figure 7 illustrates that students with 80 or higher scores are more than $70 \%$ under the teaching method of artificial intelligence technology, while the students with 80 or higher scores in the control group are only more than $40 \%$. It shows that the use of artificial intelligence technology can promote the learning achievements of students and increase the learning depth of the students. Under this method, the students' scores are all above 60 , which greatly improves the teaching efficiency.

\subsection{Analysis of learning attitude for the application of artificial intelligence teaching design}

The actual application effect of artificial intelligence technology is analyzed in teaching design from learning attitude. The analysis results are shown in Figure 8 below.

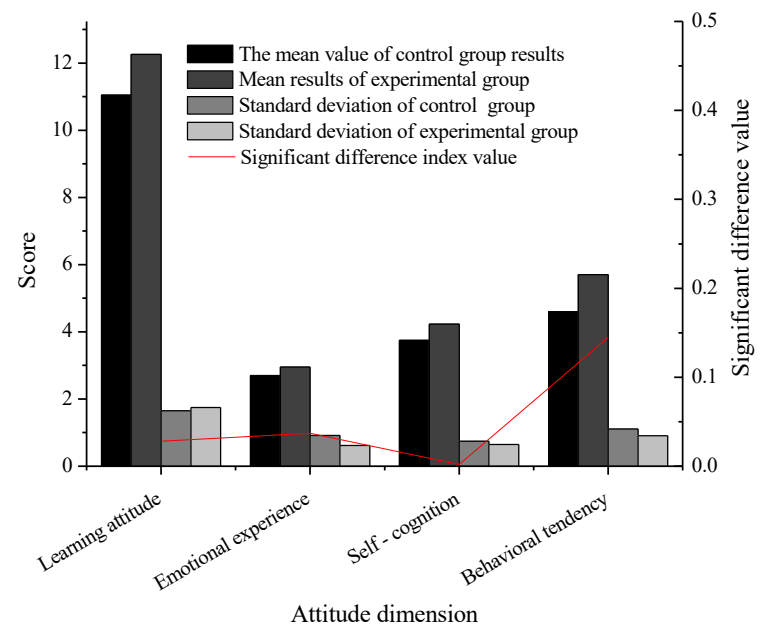

Fig. 8. Comparative analysis of students' learning attitude under different teaching design methods

Above Figure 8 indicates that the score of students under the teaching design method based on artificial intelligence technology is higher in learning attitude, emotional experience, self-cognition, and behavioral tendency than that in the control group. In addition, the significant difference indicator suggests that there is no significant difference between the two only in terms of behavioral tendency. It shows that artificial intelligence technology can promote the cognition and learning ability of students to a certain extent, thereby improving the learning and teaching efficiency.

\subsection{Analysis of teaching satisfaction for the application of artificial intelligence teaching design}

The actual application effect artificial intelligence technology is analyzed in teaching design from teaching satisfaction. The application satisfaction of the added 
creative programming courses is analyzed mainly by improving the interest and enthusiasm in learning and personal acceptance, mastering the functions and properties of components, and deepening the understanding and application of code blocks. The analysis results are shown in Figure 9 below.

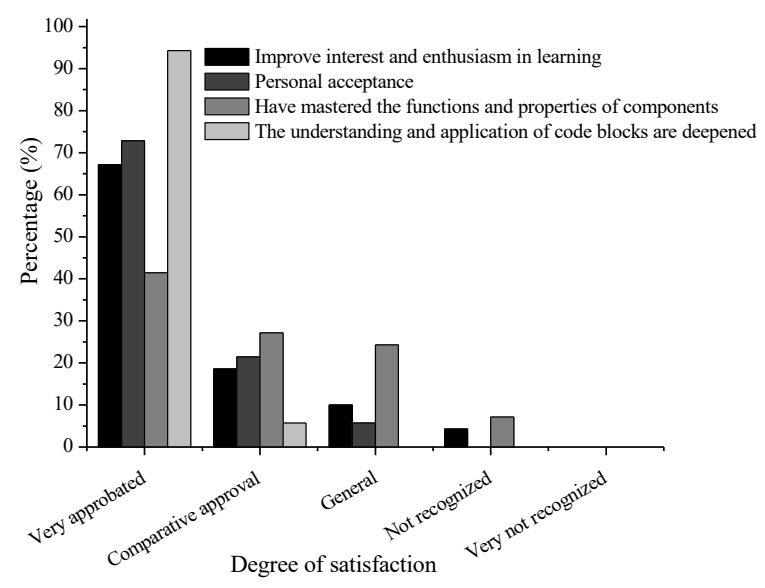

Fig. 9. Analysis results of student satisfaction

Figure 9 reveals that teaching activities based on the artificial intelligence teaching design have achieved more than $90 \%$ satisfaction in improving the interest and enthusiasm in learning, personal acceptance, mastering the functions and properties of components, as well as deepening the understanding and application of code blocks. It proves that teaching activities based on the artificial intelligence teaching design can be applied to actual teaching activities, thereby improving teaching efficiency and learning efficiency.

\section{Conclusion}

The impact of artificial intelligence technology on teaching design is explored in this study. First, artificial intelligence is introduced and its impacts on teaching design are analyzed. It is found that the application of artificial intelligence technology has led to different levels of change in the six elements of teaching design, including teaching objectives, service objects (teachers and students), teaching contents, teaching media, teaching environment, and teaching evaluation. Then, the connotation of teaching design and the paradigm shift for teaching design are explored using the paradigm shift analysis framework. The investigation shows that the connotation and paradigm shift of the teaching design can be introduced from the four elements based on the artificial intelligence technology. Finally, the changes in teaching design under artificial intelligence is analyzed, and the impact of artificial intelligence on teaching activities is investigated. It is found that artificial intelligence technology can enhance 
the learning ability and cognitive ability of students to a certain extent while improving the teaching efficiency and learning efficiency.

Due to the limitation of time and space as well as the author's limited level of knowledge, it is found throughout the previous results that there are few relevant achievements in the connotation analysis of the teaching design and paradigm shift of artificial intelligence technology. Therefore, there are still some deficiencies in the content. At the same time, the artificial intelligence technology is constantly developing. Thus, the viewpoints in this investigation still have one-sidedness. It is hoped that in the follow-up, relevant knowledge can be continuously expanded to improve the depth and comprehensiveness.

\section{Acknowledgement}

This work was supported by China Jiangsu Province Educational Science "13th Five-Year Plan" Project: Construction of an innovative leisure sports talent training system based on vocational adaptability(NO.D/2018/01/70)

\section{References}

[1] Popenici, S. A. D. Kerr, S. (2017). Exploring the impact of artificial intelligence on teaching and learning in higher education. Research \& Practice in Technology Enhanced Learning, 12(1): 22 https://doi.org/10.1186/s41039-017-0062-8

[2] Roll, I. Wylie, R. (2016). Evolution and revolution in artificial intelligence in education. International Journal of Artificial Intelligence in Education, 26(2): 582-599 https://doi.org/ 10.1007/s40593-016-0110-3

[3] Timms, Michael, J. (2016). Letting artificial intelligence in education out of the box: educational cobots and smart classrooms. International Journal of Artificial Intelligence in Education, 26(2): 701-712 https://doi.org/10.1007/s40593-016-0095-y

[4] Brundage, M. (2015). Economic possibilities for our children: artificial intelligence and the future of work, education, and leisure. acta botanica croatica, 61(8): 11-26

[5] Conati, C. Heffernan, N. Mitrovic, A. Verdejo, M. F. (2015). [lecture notes in computer science] artificial intelligence in education volume $9112 \|$ motivational design in an intelligent tutoring system that helps students make good task selection decisions. 10.1007/978-3-319-19773-9(Chapter 23): 226-236 https://doi.org/10.1007/978-3-31919773-9 23

[6] Wong, G. K. W. Ma, X. Dillenbourg, P. Huan, J. (2020). Broadening artificial intelligence education in k-12: where to start? ACM Inroads, 11(1): 20-29 https://doi.org/10.1145/ $\underline{3381884}$

[7] Chrisinger, D. (2019). The solution lies in education: artificial intelligence \& the skills gap. On the Horizon, 27(1): 1-4 https://doi.org/10.1108/OTH-03-2019-096

[8] Eaton, E. Machado, T. Williams, T. Koenig, S. Schulz, C. Maurelli, F. et al. (2018). Blue sky ideas in artificial intelligence education from the eaai 2017 new and future ai educator program. AI Matters, 3(4): 23-31 https://doi.org/10.1145/3175502.3175509

[9] Matthew, B. Abigail, F. (2015). Learning beyond the screen: assessing the impact of reflective artificial intelligence technology on the development of emergent literacy skills. plant physiology, 151(2): 681-690 
[10] Duong, M. T. Rauschecker, A. M. Rudie, J. D. Chen, P. H. Mohan, S. (2019). Artificial intelligence for precision education in radiology. British Journal of Radiology, 92(1103): 20190389 https://doi.org/10.1259/bjr.20190389

[11] Biswas, G. Segedy, J. R. Bunchongchit, K. (2016). From design to implementation to practice a learning by teaching system: betty's brain. International Journal of Artificial Intelligence in Education, 26(1): 350-364 https://doi.org/10.1007/s40593-015-0057-9

[12] Renée M. (1999). Teaching the artificial intelligence course:online resources that can help a lot!. Acm Sigcse Bulletin, 31(2): 21-22 https://doi.org/10.1145/571535.571552

[13] Buse, K. Hawkes, S. (2015). Health in the sustainable development goals: ready for a paradigm shift? Globalization \& Health, 11(1): 13 https://doi.org/10.1186/s12992-015$\underline{0098-8}$

[14] Mandal, P. Flosi, A. Large, J. (2016). Paradigm shift in teaching it-based courses in a teaching university. International journal of business information systems, 21(3): 342-352 https://doi.org/10.1504/IJBIS.2016.074765

[15] Evans, M. A. Nino, M. Deater-Deckard, K. Chang, M. (2015). School-wide adoption of a mathematics learning game in a middle school setting: using the tpack framework to analyze effects on practice. Asia Pacific Education Researcher, 24(3): 495-504 https://doi.org/10.1007/s40299-014-0225-y

[16] Suppes, P. Morningstar, M. (1969). Computer-assisted instruction. Science, 166(3903): 343-350 https://doi.org/10.1126/science.166.3903.343

[17] Riggs, B. Poli, C. Woolf, B. (1998). A multimedia application for teaching design for manufacturing. Journal of Engineering Education, 87(1): 63-69 https://doi.org/10.1002/ j.2168-9830.1998.tb00323.x

\section{$7 \quad$ Authors}

Jian Huang is a doctor of philosophy in education major in physical education on a probationary status candidate, associate professor, His interests are Philosophy of education and physical education.

Gang Shen is a doctor of Education, associate professor, His interests are sports for leisure.

Xiping Ren is a PhD candidate in the Universitätsmedizin Rostock. His interests are physical education and sports medicine.

Article submitted 2020-12-07. Resubmitted 2021-01-14. Final acceptance 2021-01-15. Final version published as submitted by the authors. 